\title{
Engaging community women's groups to improve maternal health care delivery in Cross River: Implementation research report
}

\author{
Pooja Sripad \\ Population Council \\ Emmanuel Nwala \\ Tracy McClair \\ Population Council \\ Salisu Mohammed Ishaku \\ Population Council \\ Charlotte E. Warren \\ Population Council
}

Follow this and additional works at: https://knowledgecommons.popcouncil.org/departments_sbsr-rh

Part of the Demography, Population, and Ecology Commons, Family, Life Course, and Society Commons, International Public Health Commons, Maternal and Child Health Commons, and the Medicine and Health Commons

How does access to this work benefit you? Let us know!

\section{Recommended Citation}

Sripad, Pooja, Emmanuel Nwala, Tracy McClair, Salisu Mohammed Ishaku, and Charlotte E. Warren. 2019. "Engaging community women's groups to improve maternal health care delivery in Cross River: Implementation research report," Ending Eclampsia Final Research Report. Washington, DC: Population Council. 


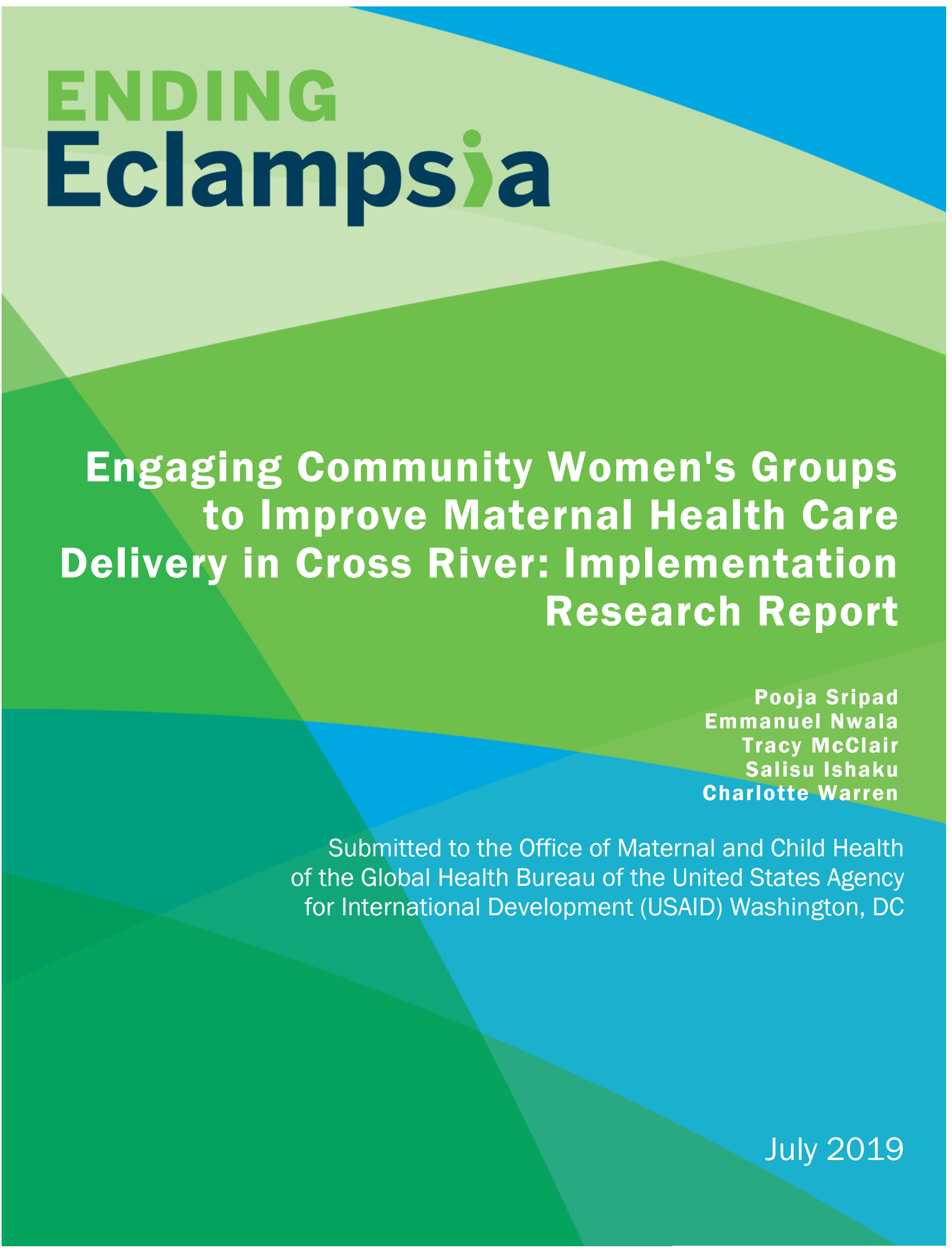




\section{ENDING}

Ending Eclampsia seeks to expand access to proven, under-utilized interventions and commodities for the prevention, early detection, and treatment of pre-eclampsia and eclampsia and strengthen global partnerships.

\section{POPULATION COUNCIL \\ Ideas. Evidence. Impact.}

The Population Council confronts critical health and development issues-from stopping the spread of HIV to improving reproductive health and ensuring that young people lead full and productive lives. Through biomedical, social science, and public health research in 50 countries, we work with our partners to deliver solutions that lead to more effective policies, programs, and technologies that improve lives around the world. Established in 1952 and headquartered in New York, the Council is a non-governmental, non-profit organization governed by an international board of trustees.

Population Council

4301 Connecticut Avenue NW, \#280

Washington DC, 20008

Tel: +1. 877.237.9400

www.popcouncil.org

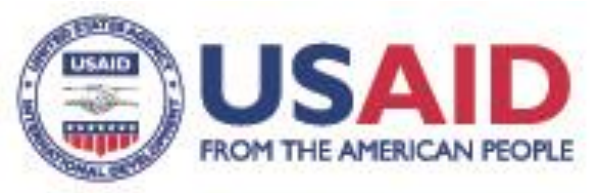

The Ending Eclampsia project is made possible by the generous support of the American people through the United States Agency for International Development (USAID) under the terms of USAID APS-OAA-A-14-00048. The contents of this report are the sole responsibility of the Ending Eclampsia project and the Population Council and do not necessarily reflect the views of USAID or the United States Government.

(c) 2019 The Population Council, Inc. 


\section{Table of Contents}

List of Abbreviations...................................................................................................................4

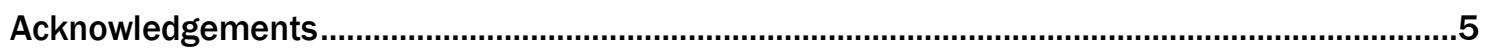

Executive Summary.........................................................................................................................6

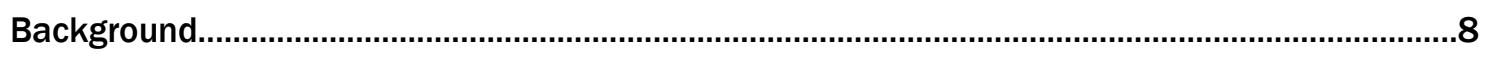

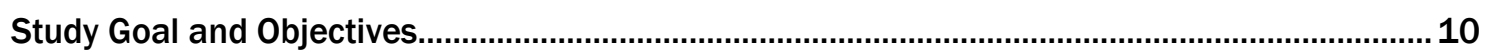

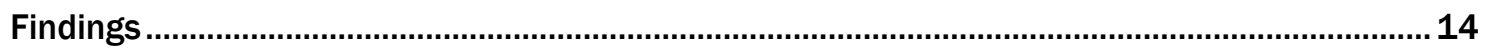

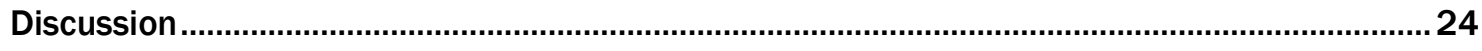

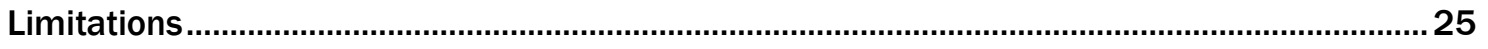

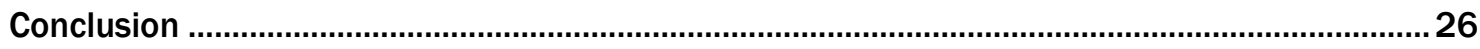

Recommendations ........................................................................... Error! Bookmark not defined.

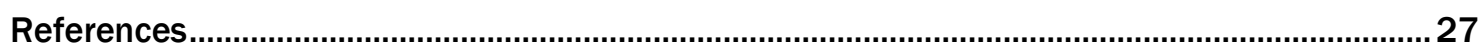

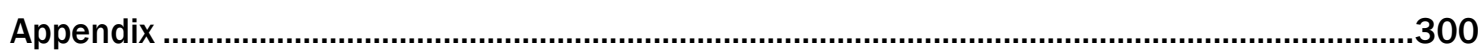




\section{List of Acronyms}

\begin{tabular}{ll} 
ANC & Antenatal Care \\
BP & Blood Pressure \\
FMoH & Federal Ministry of Health \\
HDP & Hypertensive Disorder in Pregnancy \\
HTN & Hypertension \\
LGA & Local Government Area \\
NDHS & Nigeria Demographic and Health Survey \\
LMIC & Low- and Middle Income Country \\
PE/E & Pre-Eclampsia/Eclampsia \\
PHC & Primary Health Care \\
PNC & Postnatal Care \\
SMGL & Saving Mothers, Giving Life \\
SMoH & State Ministry of Health \\
WHO & World Health Organization \\
USAID & United States Agency for International Development \\
\hline
\end{tabular}




\section{Acknowledgements}

We acknowledge all stakeholders (professional associations and implementing partners) who provided valuable inputs during the study and dissemination of findings. The successful completion of this research would not have been possible without the enabling environment provided by the Cross River State Ministry of Health and the dedication of Women's Group Leaders in the participating communities. We further acknowledge all the study participants, who gave their time and provided valuable information during the study. 


\section{Executive Summary}

Women's groups are associated with increased access to health services and improved health outcomes in low- and middle-income settings) ${ }^{1}$. In Nigeria and elsewhere, little is known about the effectiveness of existing women's meeting forums or networks in raising awareness on maternal health and service options and promoting healthcare-seeking behaviors. While many women in Nigeria who experience maternal complications-including hypertensive disorders of pregnancy, pre-eclampsia and eclampsia-receive essential care, there are often delays in care seeking and provision due to persisting health system inefficiencies in quality and referral from primary to tertiary healthcare facilities across the pregnancy, childbirth, and postnatal periods. Aside from supply-side challenges, knowledge and use of maternal health services including antenatal care, delivery, and postnatal care, is low. Yet there is little to no formal documented evaluation of programs implemented through community channels in Nigeria, including group activities that aim to support women and their families and provide crucial knowledge about maternal health.

This implementation research study was embedded within the broader Ending Eclampsia project being conducted in three states. Ending Eclampsia's main objective is to improve access to underutilized interventions and commodities by training community health extension workers in preventing, detecting (screening), and managing pre-eclampsia and eclampsia. While the broader project emphasized primary health care interventions, this study focused on a community intervention in one state, in areas where the facility interventions were active. This report describes implementation research testing the feasibility and utility of employing women's groups as community platforms to increase women's access to quality antenatal service utilization, using pre-eclampsia screening as the entry point.

This study was conducted in 48 communities in 12 local government areas of Cross River state in southern Nigeria; sites were jointly selected with the State Ministry of Health. Data were collected before and after implementation of a training intervention for 48 women leaders in 24 intervention communities. This specific intervention included workshops for women's group leaders on how to deliver relevant health information using pictorial job aids during participatory women's group meetings. The study communicated pre-eclampsia awareness as the entry point for discussing hypertension in pregnancy, the importance of blood pressure measurement, testing for proteinuria, and the signs and symptoms of pre-eclampsia. The comparison communities' women's group leaders received no training nor mentorship.

The State Ministry of Health, in collaboration with the Ending Eclampsia research team, conducted two review meetings three months after the initial training to identify and address implementation gaps and to enable women's group leaders to reflect on their experiences and those of their peers. Following this, the State Ministry of Health institutionalized periodic monitoring of the groups and appointed a senior nurse to mentor the women's group leaders to ensure the sustainability of the intervention. The nurse/mentor intermittently attended the communication sessions to provide further guidance and clarity to women's questions where necessary and supported women's group leaders to identify other platforms to disseminate health information.

1 World Health Organization (WHO). WHO Recommendations on Antenatal Care for a Positive Pregnancy Experience: Summary. World Health Organization. Geneva, Switzerland: WHO; 2018. Licence: CC BY-NC-SA 3.0 IGO. 
Women's group leaders held 289 sessions, resulting in 16,031 contacts with women. At endline, in general women in the intervention group reported better ANC clinical experiences including higher quality of care, when compared to baseline. Women in the intervention group were more likely at endline to have had their blood pressure checked, results explained, proteinuria test, implications of proteinuria test explained, received information about signs of pregnancy complications, their weight measured, and told about their weight, compared to women at baseline. Further, women were more likely to ask providers questions and receive results of their health checks at endline compared to baseline in the intervention group. Some of these improvements were seen in the comparison group as well, likely due to the broader Ending Eclampsia work at facility level.

Women's knowledge about maternal health complications also improved from baseline to endline among women in the intervention group. Specifically, more women in the intervention group had heard about pre-eclampsia, had heard that pre-eclampsia is associated with high blood pressure and proteinuria, and were aware of at least three danger signs in pregnancy at endline compared to baseline. Women in the comparison group also had some knowledge improvements. Moreover, women received information through women's group activities-either presented during the women's group meetings or by women's group leaders in churches-in the intervention group at endline compared to baseline. Among these women, there were high levels of knowledge about pre-eclampsia and eclampsia at endline.

A quarterly review of service uptake data at primary health care facilities in intervention communities indicated that there was higher antenatal care utilization one year after the start of the intervention compared to one year prior to the intervention. Similarly, the number of women who had their blood pressure and urine tested increased over the year from when the intervention was implemented compared to one year prior. Facility deliveries also appeared to increase slightly.

This implementation research shows that community women's group platforms play an important role in educating women on their health as well as improving access to and utilization of quality maternal and child health services in Nigeria. Although it is conceivable that women in the intervention group may have obtained information from other sources, this research suggests that the training and mentoring of women's group leaders was effective at improving knowledge of maternal health and increasing antenatal care service uptake. Community women and stakeholders recognize the contribution of the learning activities that take place at their community group platforms. Women are willing to participate in the health information sessions provided by women leaders during group meetings and in churches. Community engagement in Cross River is an important form of information sharing and building awareness targeting populations of reproductive age. 


\section{Background}

Hypertensive disorders of pregnancy (HDPs), especially pre-eclampsia and eclampsia (PE/E), account for an unacceptably high proportion of maternal deaths in Nigeria. The Nigeria Near-miss and Maternal Death Surveillance Network led by World Health Organization (WHO) found that almost one third of maternal deaths (29\%) in 46 tertiary hospitals were due to HDPs (mainly PE/E) and 45 percent of maternal deaths can be attributed to patient-oriented problems of late presentation to hospitals ${ }^{1}$. While many women who present with maternal complications receive essential care, often there are delays in provision of care due to persisting health system inefficiencies across the spectrum of care from primary to tertiary health care facilities ${ }^{1-2}$.

Apart from supply side inefficiencies, there are still demand side gaps that undermine women's access to essential care. Several studies in Nigeria confirm that knowledge and use of maternal health services including antenatal (ANC), delivery, and postnatal care (PNC) is low3-8. A landscape analysis conducted in seven states in Nigeria in 2015 highlighted poor community knowledge regarding HDP, specifically PE/E, with varying misconceptions about the causes ${ }^{9}$. Few women and men knew of any danger signs to be aware of during pregnancy ${ }^{10}$.

In Nigeria, programs implemented through community channels, including group activities, maintain little to no formal documented evaluation. Approaches to incorporate women's groups in facilitating access to health services have shown improved outcomes elsewhere, albeit with context-specific challenges. Factors influencing non-use of maternal health services include mothers' education, lack of trust and low perceived quality of services, lack of women's autonomy and decision-making power, and a belief that use of facilitybased maternal health services is not necessary for safe childbirth10, 11-14. Empowering women with the right information about HDPs and other emergency obstetric complications is posited to improve access to and use of maternity services and improve maternal and neonatal health outcomes ${ }^{10,15-17 .}$

Few interventions specifically target the gap between community members and health providers to improve ANC service uptake to reduce HDPs including PE/E and other pregnancy complications ${ }^{18}$. Some studies in low- and middle income countries (LMICs) have reported that consumers request specific services when they know what is available (in terms of human resources and stock) and beneficial to their health ${ }^{5,19}$. In Nigeria and elsewhere, however, little is known about the effectiveness of existing women's meeting forums or networks in promoting health care-seeking behaviors, including raising awareness of maternal health and services options ${ }^{19-22}$.

Statistics from Nigeria National Demographic and Health Survey (NDHS) 2013 indicate that 61 percent and 51 percent of pregnant women attend one and four ANC visits, respectively. Similarly, only 38 percent of deliveries were attended by a skilled birth attendant and 40 percent of women were seen by health care providers within two days of childbirth ${ }^{10}$. A landscape analysis in six states in Nigeria in 2015 , found that 67 percent of women did not know of any danger signs in pregnancy and while 91 percent had their blood pressure checked during ANC visits, only 31 percent of women reported that their health care providers explained to them what their blood pressure (BP) measurement was and its implication 23 .

This report describes findings from an implementation research study in Cross River state, informed by the health belief model, to empower and equip women of reproductive age with life-changing information through endogenous women's group platforms in the state (Figure 1). In this intervention, women's group leaders were trained on maternal and child health $(\mathrm{MCH})$ issues ranging from the purpose and benefits of attending ANC clinics, ensuring essential tests are carried out and explained, and the importance of supporting women to confidently ask their care providers questions about their health and that of their 
unborn babies. This intervention theory posits that empowering women within the community with information (awareness) through recognized trusted opinion leaders and peers (women's groups) has the potential to improve health care-seeking behavior and demand for quality maternal health services ${ }^{24}$.

Figure 1. The health belief model

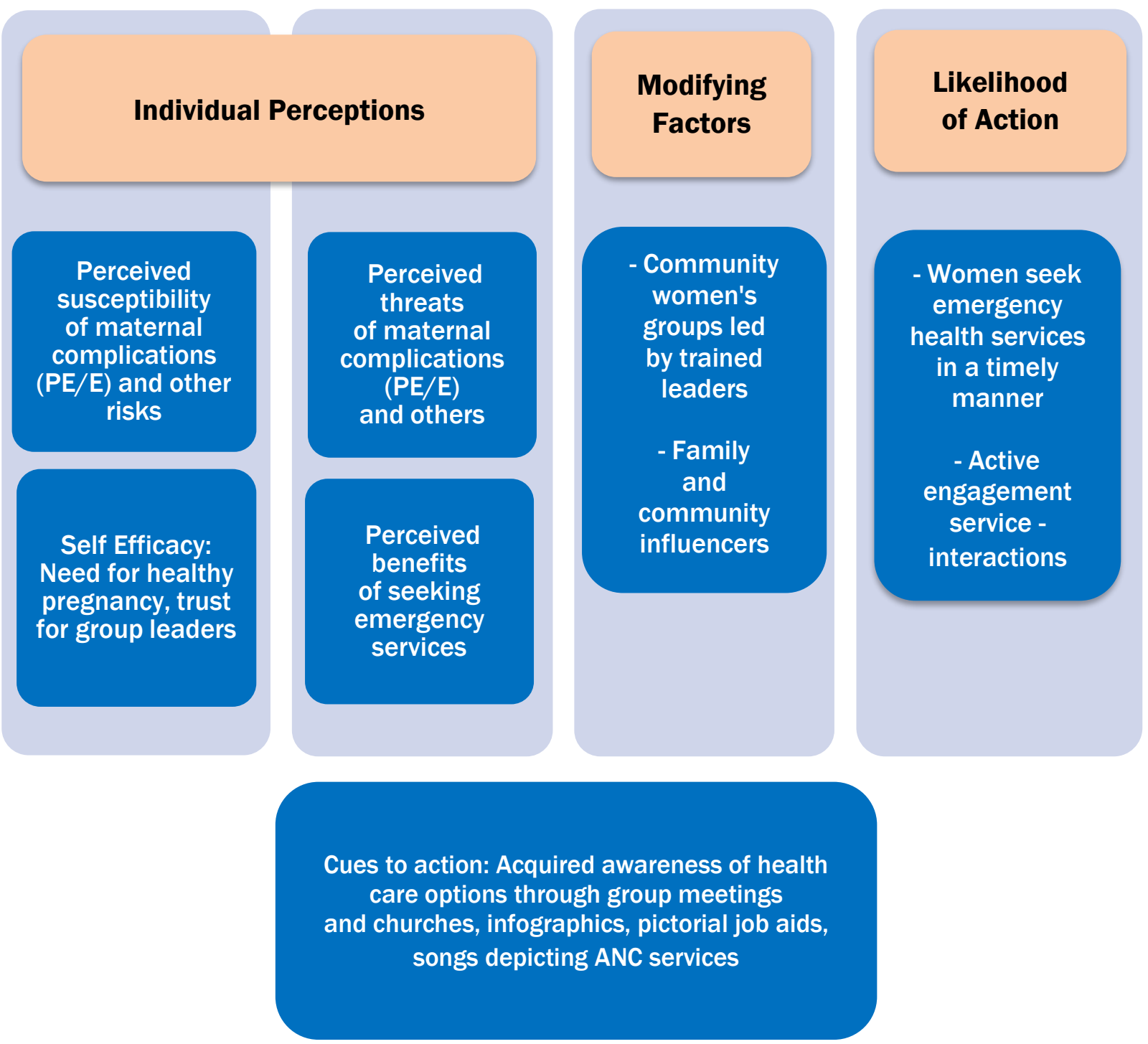




\section{Study Goal and Objectives}

The overall goal of the study is to test the feasibility and utility of employing women's groups as community platforms for reaching women with life-saving information related to $\mathrm{PE} / \mathrm{E}$ as an entry point to increase access to quality ANC service utilization.

\section{METHODOLOGY}

\section{Study Settings}

This study was conducted in 48 communities of 12 local government areas (LGAs) of Cross River state in Southern Nigeria; 24 LGAs were selected as intervention communities, while the remaining 24 were classified as comparison communities. The selected LGAs were those where the broader Ending Eclampsia Project is being implemented; a larger effort supporting the prevention, early detection and management of pre-eclampsia at lower levels of the health system ${ }^{25}$. This study focused on the community level, complementing the existing facility-strengthening activities. Figure 2 is a map of the LGAs and distribution of intervention communities in blue and comparison communities in green.

Figure 2. Intervention and comparison LGAs and communities in Cross River State

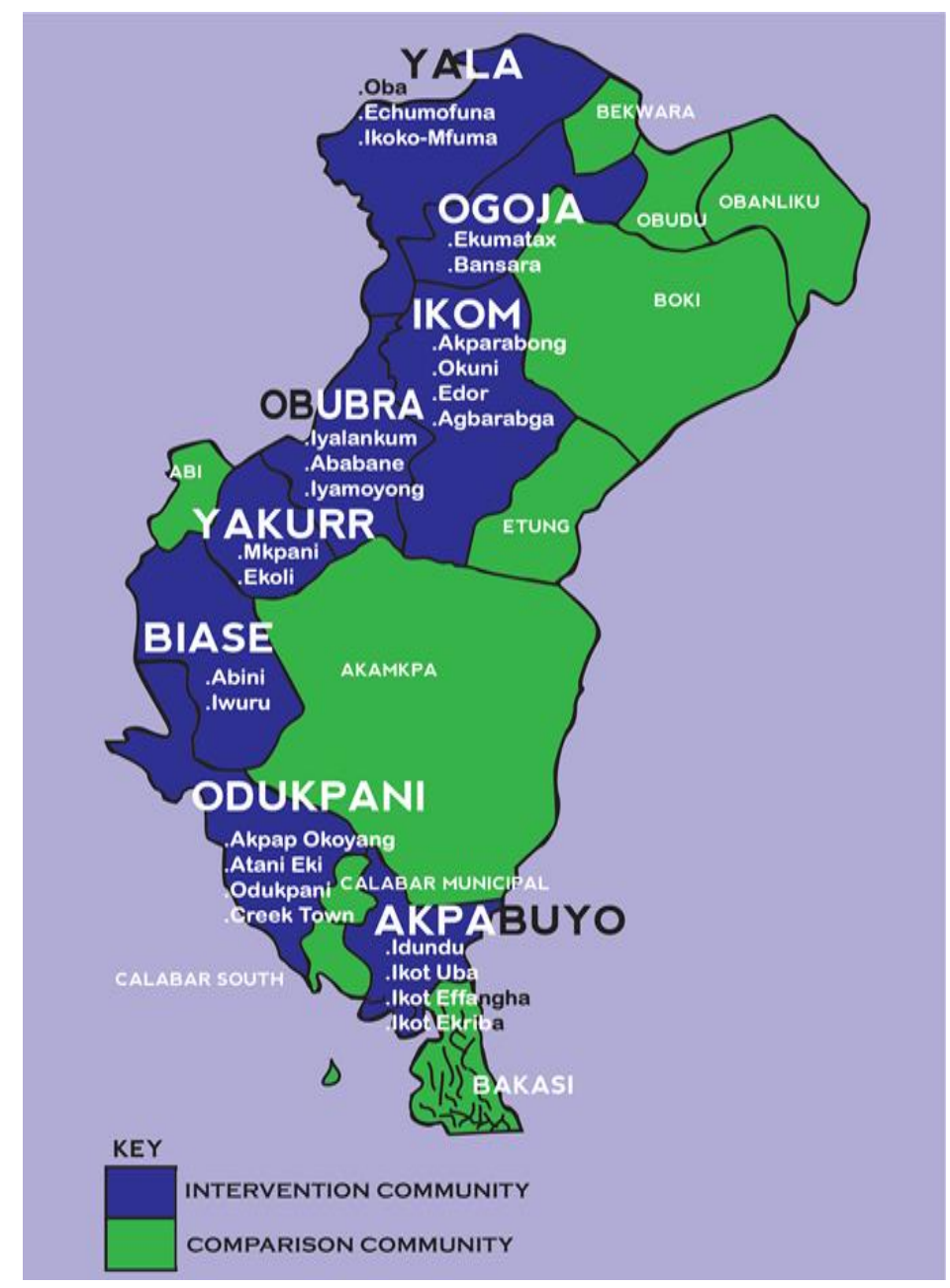




\section{Intervention Description}

The intervention included workshops for 48 women's group leaders (24 initially in August 2017 and an additional 24 following observational monitoring visits in December 2017) on how to deliver relevant health information using pictorial job aids during participatory group meetings (Appendix 1). Critical topics included early and frequent ANC attendance, signs and symptoms of pregnancy complications (and implications on both mother and infant health), what to expect during pregnancy and after delivery, birth preparedness, vaccination, the importance of a skilled provider at birth, and PNC. The study communicates pre-eclampsia awareness as the entry point for discussing HDP, the importance of BP measurement, testing for proteinuria and the signs, symptoms of pre-eclampsia, and other danger signs in pregnancy. The training also emphasized priming women on what to expect and the kind of questions to ask for during ANC contacts including BP measurement, tests results, referrals, and follow up.

Women leaders were equipped with pictorial job aids (flip chart) and infographics to enable them to provide health information to their peers. Women's group leaders developed songs that depicted key messages such as the importance of early registration for ANC, adhering to provider advice and referrals to higher level health facilities, family planning (FP) and birth spacing, emergency maternal services, and importance of facility delivery. At the end of each communication session, the leaders distributed the infographics (both English and local language versions) for participants to take home. This process was repeated in churches and other venues where women leaders routinely provide health talks. Across LGAs, the median frequency of information sessions was once a month though ranged between one to four times a month.

The State Ministry of Health (SMoH), in collaboration with the Ending Eclampsia research team, conducted two review meetings three months after the initial training to identify and address implementation gaps and to enable women leaders to reflect on their experiences and those of their peers. SMoH institutionalized periodic monitoring of the groups in order to improve the mentoring process for women's group leaders and ensure the sustainability of the intervention.

In December 2017, the research team conducted midline evaluation observations of the groups' performance (December 2-9). Observation from the monitoring visits showed that beyond their regular meetings, women's group leaders have also used other platforms to disseminate health information including at the market or churches, during traditional council or combined men's and women's group gatherings, and ad hoc interpersonal strategies (e.g. home visits). Suggestions from the women's group leaders were integrated into the intervention and used to improve the quality and the contents of the job aids into the final versions of the flipcharts and infographics. The intervention trained an additional 24 women's group leaders from 12 new communities and equipped them with the job aids to deliver health education and information. The team printed 60 copies of flip charts (job aids) for women's group leaders to help in generating demand for a positive pregnancy experience, and 5,000 infographic flyers to circulate to women in the intervention sites.

\section{Study Population, Data Collection, Sampling and Analysis}

A quasi-experimental design with a pre-post evaluation of intervention and comparison sites was applied. Data collection was conducted before and after implementation in 24 intervention and 24 comparison communities. Specific study sites were identified with support from $\mathrm{SMoH}$.

\section{Study population}

For this study, several types of respondents were interviewed: 
1. Women's group leaders and other group members (representatives referred by women's group leaders) and leaders from each women's group that have large membership and meets regularly (at least monthly) were selected and invited to participate.

2. Pregnant women using PHC services in the study sites. All pregnant and postpartum women attending ANC and PNC clinics at the selected PHCs during the data collection period who fulfil the selection criteria were invited to participate in IDIs. Selection criteria for pregnant and postnatal women include those who are 15 years or older, pregnant (at any gestational age), or having given birth within the last six weeks, and provided informed consent.

3. Community stakeholders for focus group discussions (FGDs).

\section{Data collection}

Table 1 below describes the various data collection activities of this implementation research study in detail. We conducted IDIs with women's group leaders and members, FGDs with community men and women, and ANC client exit interviews. We also collected data from facilities in comparison and intervention communities.

Table 1. Distribution of data collection activities

\begin{tabular}{|l|c|c|c|c|}
\hline \multirow{2}{*}{} & \multicolumn{2}{|c|}{ Comparison } & \multicolumn{2}{c|}{ Intervention } \\
\cline { 2 - 5 } & Baseline & Endline & Baseline & Endline \\
\hline IDIs with women's group leaders & 10 & 10 & 14 & 18 \\
\hline IDIs with women's group members - beneficiaries & - & - & - & 12 \\
\hline FGD with community men & - & 1 & - & 1 \\
\hline FGD with community women & - & 1 & - & 1 \\
\hline ANC Client exit interview & 123 & 34 & 142 & 50 \\
\hline Facilities inventory & 24 & 24 & 24 & 24 \\
\hline
\end{tabular}

Given the endline evaluation for the women's group study was embedded within a larger evaluation exercise for Ending Eclampsia, and in light of re-classification of a number of PHCs given Nigeria's 'Primary Health Care Under One Roof Policy' that consolidated health infrastructure ${ }^{26}$, we were unable to recruit as many clients as we did at baseline for the client exit interviews at endline. During the data collection period (May and June 2018), the Joint Health Sector Union (JOHESU, minus doctors) in Nigeria embarked on a three week sector action (i.e. strike), causing all PHCs to completely cease services. Upon return of PHC operations, client flow was minimal given that clients lost trust of meeting providers at the facilities after repeated unsuccessful visits. The women's group study was implemented in selected PHCs (not secondary facilities) which were affected by the provider strikes. Additionally, while data collection was ongoing, four communities experienced heavy communal clashes (i.e. riots) resulting in fewer ANC client exit interviews at the PHCs in the affected areas. Although these community clashes were not directed against health providers, facilities were typically closed during the incidents, and providers sometimes fled from these communities until normalcy returned, resulting in non-use of services.

\section{Data management and analysis}

All paper-based questionnaires retrieved from the client files were transferred immediately to the Population Council office in Abuja for data entry and analysis. All hard copies of questionnaires, consent forms, and clients' case notes were bound and stored in secured drawers at the Council's Abuja office and will be stored for five years before being destroyed by Council staff. Descriptive and bivariate analyses (chisquare and Fisher's exact) were conducted using Epidata version 3.1 and SPSS version 20. 
Qualitative data from IDIs were digitally recorded, transcribed, translated, reviewed, and a code structure was developed collaboratively for analysis. Data were coded using Nvivo 11 software for management and analysis. Thematic analysis was applied to capture pre-identified and emerging themes.

\section{Ethical Review and Consent}

The research protocol was approved by Population Council's Institutional Review Board in New York (as Protocol 795) and Cross River State's Research Ethics Committee of the Ministry of Health (CRS/MH/ HREC/017/Vol.V1/002). Informed consent was obtained for all participants. Administrative approval was obtained from Cross River $\mathrm{SMoH}$. A senior public health nurse from $\mathrm{SMoH}$ collaborated with the research team to provide supportive supervision to the women's groups. 


\section{Findings}

This section describes the women's groups, their members, individuals who sought care at ANC facilities, and their experiences with care, after 289 group sessions and approximately 16,031 contacts with women. Group leaders' log books recorded only total participants at each session, so the number of unique women reached was unattainable. Of the 24 groups, 21 were active throughout the period of the study. (Appendix 2 provides the LGAs and characteristics of the women's group platforms in the intervention.) Only two of the group leaders are without formal education, and most have a secondary education or higher. Table 2 details the educational and employment status of group leaders as well as individual performance.

Table 2. Women's group leaders' demographic characteristics $(n=46)$

\begin{tabular}{|rr|c|c|}
\hline Education & & $\mathrm{n}$ & $\%$ \\
\hline & No Education & 2 & 4.3 \\
\hline & Primary & 2 & 4.3 \\
\hline & Secondary & 29 & 63.0 \\
\hline Occupation & Tertiary & 13 & 28.1 \\
\hline & & $\mathrm{n}$ & $\%$ \\
\hline & Farming & 31 & 67.4 \\
\hline & Civil servant & 4 & 8.7 \\
\hline & Teaching & 8 & 17.4 \\
\hline & Trading & 2 & 4.3 \\
\hline Mean Age & Religious leader & 1 & 2.2 \\
\hline & & \multicolumn{2}{|c|}{43.3 years } \\
\hline
\end{tabular}

\section{ANC CLIENT EXIT INTERVIEWS}

Most women who participated in ANC client exit interviews were aged 25 to 30, married, with secondary educations, residing at their current domicile for one to five years, and Christian (Table 3). The comparison group showed significant differences in marital status, co-wives, and current residence duration, baseline to endline, while the intervention showed significant differences in education, co-wives, and residence.

Table 3. Women's baseline and endline socio-demographic characteristics

\begin{tabular}{|c|c|c|c|c|c|c|}
\hline & \multicolumn{3}{|c|}{ Comparison (\%) } & \multicolumn{3}{|c|}{ Intervention (\%) } \\
\hline & $\begin{array}{l}\text { Baseline } \\
(n=123)\end{array}$ & $\begin{array}{l}\text { Endline } \\
(n=34)\end{array}$ & $p$-value & $\begin{array}{l}\text { Baseline } \\
(n=142)\end{array}$ & $\begin{array}{c}\text { Endline } \\
(n=50)\end{array}$ & $\mathrm{p}$-value \\
\hline \multicolumn{7}{|l|}{ Age } \\
\hline $15-19$ & 14 (11.4) & $5(14.7)$ & \multirow{5}{*}{$0.405 *$} & $12(8.5)$ & $6(12.0)$ & \multirow{5}{*}{0.181} \\
\hline $20-24$ & $37(30.1)$ & $8(23.5)$ & & $43(30.3)$ & $14(28.0)$ & \\
\hline $25-30$ & $43(35.0)$ & $14(41.2)$ & & $54(38.0)$ & $14(28.0)$ & \\
\hline$>30$ & $25(20.3)$ & $4(11.8)$ & & $28(19.7)$ & $10(20.0)$ & \\
\hline No response & $4(3.3)$ & $3(8.8)$ & & $5(3.5)$ & $6(12.0)$ & \\
\hline \multicolumn{7}{|l|}{ Education } \\
\hline No education & $5(4.1)$ & $3(8.8)$ & \multirow{5}{*}{0.281 * } & $3(2.1)$ & $2(4.0)$ & \multirow{5}{*}{0.005} \\
\hline Primary & $27(22.0)$ & $5(14.7)$ & & 37 (26.1) & $3(6.0)$ & \\
\hline Secondary & 76 (61.8) & $21(61.8)$ & & $88(62)$ & $35(70.0)$ & \\
\hline$>$ Secondary & $15(12.2)$ & $4(11.8)$ & & $14(9.9)$ & $10(2.0)$ & \\
\hline No response & 0 & 2.9 & & 0 & 0 & \\
\hline
\end{tabular}




\begin{tabular}{|c|c|c|c|c|c|c|}
\hline \multicolumn{7}{|l|}{ Religion } \\
\hline Christian & $121(98.4)$ & $34(100.0)$ & \multirow{3}{*}{$1.000 *$} & $140(98.6)$ & $50(100.0)$ & \multirow{3}{*}{$1.000 *$} \\
\hline Muslim & $1(0.8)$ & 0 & & $1(0.7)$ & 0 & \\
\hline No religion & $1(0.8)$ & 0 & & $1(0.7)$ & 0 & \\
\hline \multicolumn{7}{|l|}{ Marital status } \\
\hline Single & $34(27.6)$ & $3(8.8)$ & \multirow{3}{*}{$<0.001 *$} & $30(21.1)$ & $7(14.0)$ & \multirow{3}{*}{$0.485^{*}$} \\
\hline Married & $89(72.4)$ & $27(79.4)$ & & $111(78.2)$ & $43(86.0)$ & \\
\hline Divorced/separated & 0 & 4 (11.7) & & $1(0.7)$ & 0 & \\
\hline \multicolumn{7}{|l|}{ Co-wives } \\
\hline Yes & $7(5.7)$ & $6(17.6)$ & \multirow{3}{*}{$<0.001 *$} & $11(7.8)$ & $4(8.0)$ & \multirow{3}{*}{$<0.001 *$} \\
\hline No & $116(94.3)$ & 25 (73.5) & & $131(92.3)$ & $40(80.0)$ & \\
\hline No response & 0 & $3(8.8)$ & & 0 & $6(12.0)$ & \\
\hline \multicolumn{7}{|c|}{ Duration at current residence } \\
\hline$<1 y r$ & $17(13.8)$ & $0(0.0)$ & \multirow{4}{*}{$<0.001 *$} & $9(6.3)$ & $1(2.0)$ & \multirow{4}{*}{$<0.001 *$} \\
\hline 1-5yrs & $50(40.7)$ & $16(47.1)$ & & $67(47.2)$ & $26(52.0)$ & \\
\hline$>5 y r s$ & $56(45.5)$ & $5(14.7)$ & & $66(46.5)$ & $14(28.0)$ & \\
\hline Can't recall & 0 & $13(38.2)$ & & 0 & $9(18.0)$ & \\
\hline
\end{tabular}

Cross River women have limited opportunities for income earning and decision-making. Most women in both the comparison and intervention groups are not the primary income earners. A greater proportion of women in the intervention group reported that their partner made decisions about health care, compared to themselves, at both data collection points. Significantly more women reported it as "easy" or "very easy" to afford N 2,250 (\$6.25) for health care at endline, compared to baseline, in the intervention group $(p=0.002)$; there was no difference in the comparison group (Table 4). Few women reported having health insurance-only four (8.0\%) at endline in the intervention group.

Table 4. Women's baseline and endline autonomy for health care decision-making

\begin{tabular}{|c|c|c|c|c|c|c|}
\hline & \multicolumn{3}{|c|}{ Comparison (\%) } & \multicolumn{3}{|c|}{ Intervention (\%) } \\
\hline & $\begin{array}{l}\text { Baseline } \\
(n=123)\end{array}$ & $\begin{array}{l}\text { Endline } \\
(n=34)\end{array}$ & p-value & $\begin{array}{l}\text { Baseline } \\
(n=142)\end{array}$ & $\begin{array}{l}\text { Endline } \\
(n=50)\end{array}$ & p-value \\
\hline \multicolumn{7}{|l|}{ Primary income earner } \\
\hline Self & $4(3.3)$ & $5(14.7)$ & \multirow{4}{*}{$0.025 *$} & $5(3.5)$ & $4(8.0)$ & \multirow{4}{*}{0.287 * } \\
\hline Partner & $103(83.7)$ & $22(64.7)$ & & $127(89.4)$ & $44(88.0)$ & \\
\hline Parents & $14(11.4)$ & $7(20.6)$ & & $9(6.3)$ & $1(2.0)$ & \\
\hline Other relatives & $2(1.6)$ & $0(0.0)$ & & $1(0.7)$ & $1(2.0)$ & \\
\hline \multicolumn{7}{|c|}{ Household decision-making for health care } \\
\hline Self & $12(9.8)$ & $13(38.2)$ & \multirow{4}{*}{$<0.001$} & $5(3.5)$ & $4(8.0)$ & \multirow{4}{*}{0.136 * } \\
\hline Partner & $38(30.9)$ & $10(29.4)$ & & $103(72.5)$ & $31(62.0)$ & \\
\hline Both, couple & $61(49.6)$ & $6(17.7)$ & & $25(17.6)$ & $14(28.0)$ & \\
\hline Parents/other relatives & $12(9.8)$ & $5(14.7)$ & & $9(6.3)$ & $1(2.0)$ & \\
\hline \multicolumn{7}{|c|}{ Can afford N 2,250 (\$6.25) for health care } \\
\hline Very difficult & $10(8.1)$ & $1(2.9)$ & \multirow{5}{*}{$0.351 *$} & $28(19.7)$ & $1(2.0)$ & \multirow{5}{*}{0.002 * } \\
\hline Difficult & $53(43.1)$ & $19(55.9)$ & & $34(23.9)$ & $14(28.0)$ & \\
\hline Easy & $53(43.1)$ & $14(41.2)$ & & $74(52.1)$ & $30(60.0)$ & \\
\hline Very easy & $7(5.7)$ & $0(0.0)$ & & $6(4.2)$ & $3(6.0)$ & \\
\hline No response & $0(0.0)$ & $0(0.0)$ & & $0(0.0)$ & $2(4.0)$ & \\
\hline \multicolumn{7}{|c|}{ Covered by health insurance } \\
\hline Yes & 0 & 0 & - & 0 & $4(8.0)$ & $0.004^{*}$ \\
\hline
\end{tabular}


Overall, women reported improved ANC experiences at endline compared to baseline in both comparison and intervention groups, with some key differences by group (Table 5). In both groups, more women had their medical history taken by health providers, but the difference was only statistically significant in the comparison group (30.1\% vs. $70.6 \%, p<0.001$ ). Compared to baseline, significantly more women at endline had BP checked in both the intervention (63.4\% vs. $96.0 \%, p<0.001)$ and comparison groups $(61.0 \%$ vs. $100.0 \%, p<0.001)$; however, there was no change in the proportion who were told about their BP results in either group. The proportion of women who received an explanation about the implications of their BP results significantly increased from baseline to endline in both comparison ( $29.3 \%$ vs. $51.9 \%, p=0.010)$ and intervention groups ( $20.4 \%$ vs. $38.0 \%, p=0.014)$. There were significant increases in women who had a proteinuria test, received information about signs of pregnancy complications, had their weight measured, and who were told about their weight at endline compared to baseline in both comparison and intervention groups. From baseline to endline, women in intervention communities were more likely to ask questions related to their health checks (35.9\% vs. $60.0 \%, \mathrm{p}=0.003)$ and receive results from their health checks ( $27.5 \%$ vs. $48.0 \%, p=0.008)$; these positive changes were not observed in the comparison group.

Table 5. Women's baseline and endline ANC experiences

\begin{tabular}{|l|c|c|c|c|c|c|}
\hline \multirow{2}{*}{} & \multicolumn{3}{|c|}{ Comparison (\%) } & \multicolumn{3}{c|}{ Intervention (\%) } \\
\cline { 2 - 7 } & $\begin{array}{c}\text { Baseline } \\
(\mathrm{n}=123)\end{array}$ & $\begin{array}{c}\text { Endline } \\
(\mathrm{n}=34)\end{array}$ & $\mathrm{p}$-value & $\begin{array}{c}\text { Baseline } \\
(\mathrm{n}=142)\end{array}$ & $\begin{array}{c}\text { Endline } \\
(\mathrm{n}=50)\end{array}$ & $\mathrm{p}$-value \\
\hline Provider asked for medical history & $37(30.1)$ & $24(70.6)$ & $<0.001$ & $86(60.6)$ & $32(64.0)$ & 0.668 \\
\hline BP checked & $75(61.0)$ & $34(100.0)$ & $<0.001$ & $90(63.4)$ & $48(96.0)$ & $<0.001$ \\
\hline Client received BP results & $27(22.0)$ & $10(29.4)$ & 0.364 & $69(48.6)$ & $20(40.0)$ & 0.295 \\
\hline BP results explained & $36(29.3)$ & $18(52.9)$ & 0.010 & $2920.4)$ & $19(38.0)$ & 0.014 \\
\hline Proteinuria test & $72(58.5)$ & $33(97.1)$ & $<0.001$ & $61(43.0)$ & $43(86.0)$ & $<0.001$ \\
\hline Client received proteinuria results & $39(31.7)$ & $17(50.0)$ & 0.049 & $46(32.4)$ & $21(42.0)$ & 0.220 \\
\hline Proteinuria results explained & $35(28.5)$ & $11(32.4)$ & 0.659 & $51(35.9)$ & $13(26.0)$ & 0.031 \\
\hline $\begin{array}{l}\text { Client received information on signs } \\
\text { of pregnancy complications }\end{array}$ & $68(55.3)$ & $29(85.3)$ & 0.001 & $90(63.4)$ & $46(92.0)$ & $<0.001$ \\
\hline Weight measured & $94(76.4)$ & $33(97.1)$ & 0.007 & $91(64.1)$ & $47(94.0)$ & $<0.001$ \\
\hline Client informed of her weight & $94(76.4)$ & $11(32.4)$ & $<0.001$ & $91(64.1)$ & $23(46.0)$ & 0.025 \\
\hline Client asked questions of provider & $55(44.7)$ & $14(41.2)$ & 0.713 & $51(35.9)$ & $30(60.0)$ & 0.003 \\
\hline $\begin{array}{l}\text { Client received health check } \\
\text { results }\end{array}$ & $44(35.8)$ & $15(44.1)$ & 0.374 & $39(27.5)$ & $24(48.0)$ & 0.008 \\
\hline
\end{tabular}

Women in the intervention group reported improved knowledge about pre-eclampsia, eclampsia and the causes of pre-eclampsia in pregnancy from baseline to endline (Table 6). Women in the comparison group expressed significant changes in knowledge as well. Eighty-two percent of women had heard of preeclampsia at endline the intervention group compared to 32.4 percent of women in the comparison group $(p<0.001)$. Twenty-nine percent of women in the comparison group had heard of pre-eclampsia at endline compared to 35 percent at baseline (n.s.) From baseline to endline, women in the intervention group were more likely to associate pre-eclampsia with elevated BP and urine; to know signs of eclampsia; to be aware of at least three danger signs in pregnancy; and to report obstructed labor, prolonged labor, retained labor, and malaria as danger signs or complications in pregnancy. Knowledge about hypertension in pregnancy is high in both the intervention and comparison groups. 
Table 6. Women's baseline and endline knowledge of PE/E and other danger signs in pregnancy and delivery

\begin{tabular}{|l|c|c|c|c|c|c|}
\hline & \multicolumn{3}{|c|}{ Comparison (\%) } & \multicolumn{3}{c|}{ Intervention (\%) } \\
\hline & $\begin{array}{c}\text { Baseline } \\
(n=123)\end{array}$ & $\begin{array}{c}\text { Endline } \\
(n=34)\end{array}$ & $p$-value & $\begin{array}{c}\text { Baseline } \\
(n=142)\end{array}$ & $\begin{array}{c}\text { Endline } \\
(n=50)\end{array}$ & $p$-value \\
\hline Aware of pre-eclampsia (PE) & $43(35.0)$ & $10(29.4)$ & 0.545 & $46(32.4)$ & $41(82.0)$ & $<0.001$ \\
\hline $\begin{array}{l}\text { Aware of PE association } \\
\text { with high BP and proteinuria }\end{array}$ & $35(28.5)$ & $8(23.5)$ & 0.569 & $43(30.3)$ & $35(70.0)$ & $<0.001$ \\
\hline Knows signs of eclampsia & $12(9.8)$ & $14(41.2)$ & $<0.001$ & $22(15.5)$ & $29(58.0)$ & $<0.001$ \\
\hline $\begin{array}{l}\text { Aware of at least three } \\
\text { danger signs in pregnancy }\end{array}$ & $1(0.8)$ & $22(64.7)$ & $<0.001 *$ & $15(10.6)$ & $42(84.0)$ & $<0.001$ \\
\hline $\begin{array}{l}\text { Thinks pregnant women can } \\
\text { develop HDP }\end{array}$ & $90(73.2)$ & $25(73.5)$ & 0.967 & $11681.7)$ & $45(90.0)$ & 0.170 \\
\hline $\begin{array}{l}\text { Reported obstructed labor } \\
\text { as danger sign, complication }\end{array}$ & $4(3.3)$ & $16(47.1)$ & $<0.001$ & $34(23.9)$ & $19(38.0)$ & 0.056 \\
\hline $\begin{array}{l}\text { Reported prolonged labor } \\
\text { as danger sign, complication }\end{array}$ & $15(12.2)$ & $26(76.5)$ & $<0.001$ & $33(23.2)$ & $32(64.0)$ & $<0.001$ \\
\hline $\begin{array}{l}\text { Reported retained placenta } \\
\text { as danger sign, complication }\end{array}$ & $13(10.6)$ & $14(41.2)$ & $<0.001$ & $32(22.5)$ & $23(46.0)$ & 0.002 \\
\hline $\begin{array}{l}\text { Reported malaria as a danger } \\
\text { sign, complication }\end{array}$ & $66(53.7)$ & $30(88.2)$ & $<0.001$ & $86(60.6)$ & $45(90.0)$ & $<0.001$ \\
\hline
\end{tabular}

*Fisher's exact test

A greater proportion of women in intervention communities, compared to baseline, received information through women's group activities (whether at group meetings only, from group leaders in churches only, or both) at endline (Table 7). Eighty percent of intervention participants at endline reported receiving information from both women's group activities compared to 2.8 percent at baseline $(p<0.001)$. Only 2.4 percent of women in the comparison group at baseline, and 5.9 percent at endline, received information from both women's group activities (n.s.). There was a significant increase at endline in the intervention group of women who receive information from neighbors, suggesting information-sharing within communities may be increasing as a result of women's group activities ( $16.9 \%$ vs. $30.0 \%, p=0.048)$. There was no significant increase in reports of information from health facilities in either intervention or control groups; when dis-aggregated, for women who reported their sources of health information, those who received messages from church only presentations accounted for 60 percent, while those who received messages from women's groups (only) accounted for 52 percent. No women in the intervention or comparison groups reported information on maternal health issues from women's group meetings only. In contrast, 52 percent of women in the intervention group and 5.9 percent of women in the comparison group reported information at women's group meetings only at endline $(p<0.001$ and $p=0.046$, respectively).

Table 7. Baseline and endline sources of health information

\begin{tabular}{|l|c|c|c|c|c|c|}
\hline & \multicolumn{3}{|c|}{ Comparison (\%) } & \multicolumn{3}{c|}{ Intervention (\%) } \\
\hline & $\begin{array}{c}\text { Baseline } \\
(n=123)\end{array}$ & $\begin{array}{c}\text { Endline } \\
(n=34)\end{array}$ & p-value & $\begin{array}{c}\text { Baseline } \\
(n=142)\end{array}$ & $\begin{array}{c}\text { Endline } \\
(n=50)\end{array}$ & $p$-value \\
\hline Both group meetings and church & $3(2.4)$ & $2(5.9)$ & $0.296^{*}$ & $4(2.8)$ & $40(80.0)$ & $<0.001^{*}$ \\
\hline Church only & $3(2.4)$ & $0(0.0)$ & $1.000^{*}$ & $4(2.8)$ & $30(60.0)$ & $<0.001^{*}$ \\
\hline Radio & $21(17.1)$ & $2(5.9)$ & $0.168^{*}$ & $14(9.9)$ & $2(4.0)$ & $0.247^{*}$ \\
\hline Neighbors & $22(17.9)$ & $10(29.4)$ & 0.140 & $24(16.9)$ & $15(30.0)$ & 0.048 \\
\hline Health provider at facility & $81(65.9)$ & $24(70.6)$ & 0.604 & $96(67.6)$ & $32(64.0)$ & 0.642 \\
\hline Women's group meeting only & $0(0.0)$ & $2(5.9)$ & $0.046^{*}$ & $0(0.0)$ & $26(52.0)$ & $<0.001^{*}$ \\
\hline
\end{tabular}

${ }^{\star}$ Fisher's exact test 
There was a significant increase in awareness of women's group activities on pregnancy topics among women in the intervention group from baseline to endline $(1.4 \%$ vs. $86.0 \%, p<0.001)$ (Table 8$)$. Awareness of women's group activities remained low at endline among those in the comparison group (1.6\% vs. 5.9\%, n.s.). Around three quarters of women in the intervention group reported ever participating in a WGM to discuss pregnancy-related issues, a significant increase from baseline $(0.7 \%$ to $76.0 \%, p<0.001)$, in contrast to no change low frequency of women's group participation in the comparison group. Sixty-four percent of women in the intervention group at endline reported ever participating in a women's group when PE/E was discussed, compared to none at baseline $(p<0.001)$.

Table 8. Women's baseline and endline participation in women's group activities

\begin{tabular}{|l|c|c|c|c|c|c|}
\hline & \multicolumn{3}{|c|}{ Comparison (\%) } & \multicolumn{3}{c|}{ Intervention (\%) } \\
\hline & $\begin{array}{c}\text { Baseline } \\
(n=123)\end{array}$ & $\begin{array}{c}\text { Endline } \\
(n=34)\end{array}$ & $p$-value & $\begin{array}{c}\text { Baseline } \\
(n=142)\end{array}$ & $\begin{array}{c}\text { Endline } \\
(n=50)\end{array}$ & $p$-value \\
\hline Aware of group activities on pregnancy & $2(1.6)$ & $2(5.9)$ & $0.205^{*}$ & $2(1.4)$ & $43(86.0)$ & $<0.001 *$ \\
\hline Ever participated to discuss pregnancy & $1(0.8)$ & $1(2.9)$ & $0.387^{*}$ & $1(0.7)$ & $38(76.0)$ & $<0.001 *$ \\
\hline Ever participated when PE/E discussed & 0 & $1(2.9)$ & $0.217^{*}$ & $0(0.0)$ & $32(64.0)$ & $<0.001 *$ \\
\hline
\end{tabular}

*Fisher's exact test

At endline, among women who participated in women's group activities (and at church) in the intervention group, women reported high levels of knowledge about pre-eclampsia, its causes, hypertension in pregnancy, and two or three danger signs in pregnancy (Table 9). Only 60 percent had knowledge about eclampsia, however. Eighty-three percent of these women said they had participated in women's group activities where health pregnancy issues were discussed, and 68 percent said they had ever participated in group activities where PE/E was discussed. The sample sizes of women receiving information through women's groups at baseline $(n=3)$ and endline $(n=2)$ in the comparison group, as well as at baseline in the intervention group $(n=4)$, were too small to make meaningful comparisons.

Table 9. Women's knowledge, from both women's groups and church of pregnancy issues, endline

\begin{tabular}{|l|c|}
\hline$(\mathrm{n}=40)$ & $\mathrm{n}(\%)$ \\
\hline Aware of pre-eclampsia & $37(92.5)$ \\
\hline Aware of causes of pre-eclampsia & $32(80.0)$ \\
\hline Aware of eclampsia & $24(60.0)$ \\
\hline Aware of hypertension in pregnancy & $36(90.0)$ \\
\hline Knew at least two danger signs in pregnancy & $34(85.0)$ \\
\hline Knew at least three danger signs in pregnancy & $33(82.5)$ \\
\hline ever participated in women's group activities where healthy pregnancy issues were discussed & $33(82.5)$ \\
\hline Ever participated in women's group activities where PE/E were discussed & $27(67.5)$ \\
\hline
\end{tabular}




\section{SERVICE UTILIZATION AT HEALTH FACILITIES}

We collected and compared quarterly service uptake data from PHC facilities within the 24 intervention communities one year prior to the intervention and during the nine months of intervention implementation. This was meant to serve as a proxy indicator of the influence of women's group platforms on health services uptake in facilities serving the intervention communities. Though routine figures reported in facility registers are not fully complete, trend lines suggest overall higher service use during the year following implementation (Figure 3). The decline between Q4 Baseline and Q1 Implementation reflects the start of a period of communal clashes that likely influenced service use. Facility data were ascertained from PHCs in which scale up activities related to the broader Ending Eclampsia project were ongoing.

Figure 3. Women's ANC utilization, one year preceding, and following the intervention

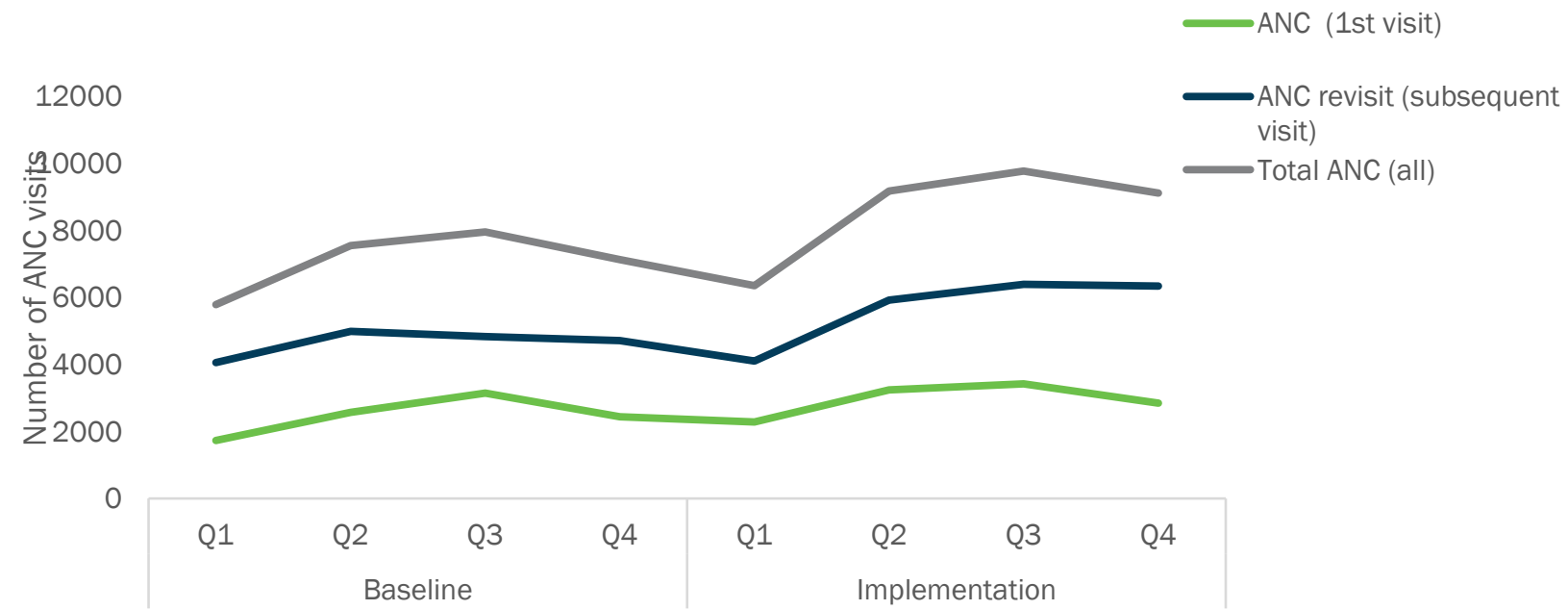

Note: Q1 of Implementation began August 2017. The intervention lasted 9 months, through the end of Q3 of the implementation period.

Similarly, the number of women who had their BP and urine tested consistently increased over the project period with the engagement of women's groups (Figure 4). CHEW health education activities at the health facilities may have increased women's requests for these services as well. Facility deliveries increased slightly during the year after implementation began compared to the preceding year.

Figure 4. Urine protein tested, BP measured, and facility deliveries, one year preceding and following

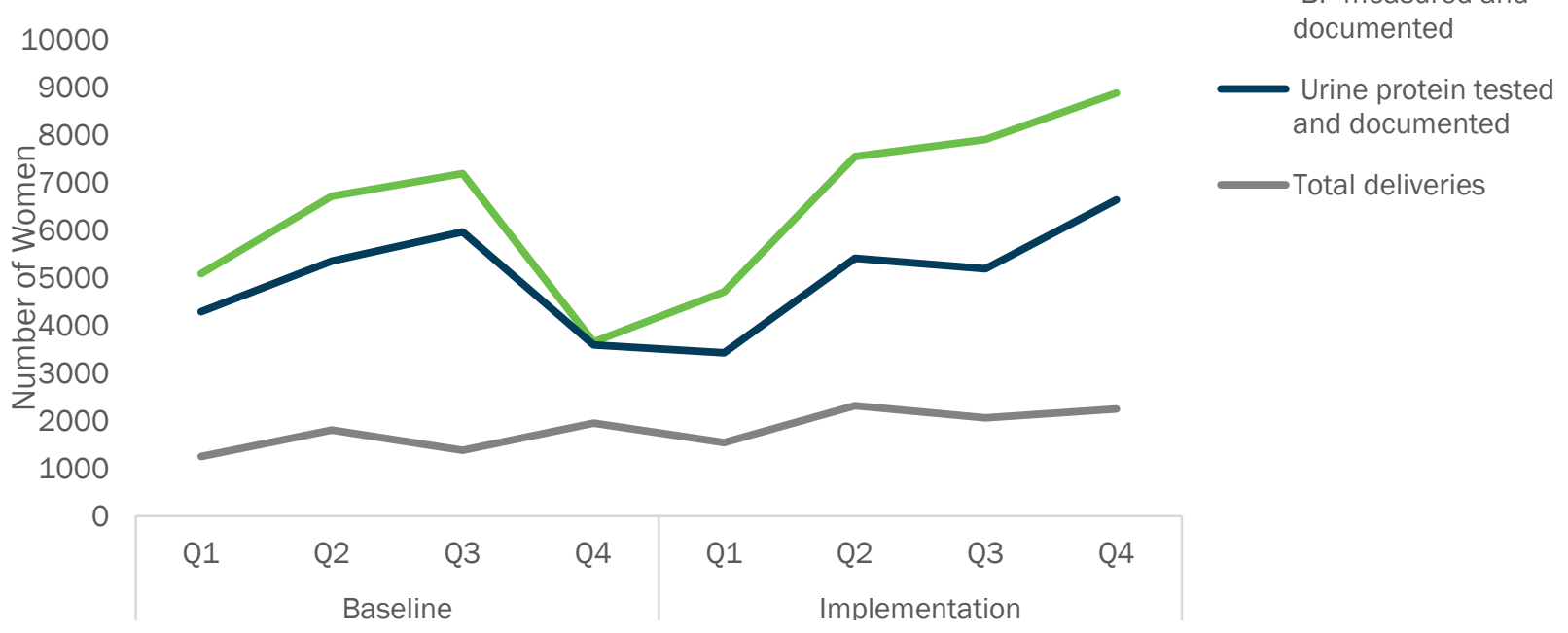




\section{IN-DEPTH INTERVIEWS AND FOCUS GROUP DISCUSSIONS}

In-depth interviews were conducted with women's group leaders and participants to understand their opinions and perceptions of their group activities. In addition, FGDs were conducted with community stakeholders to understand their opinions and perceptions of HDP and utilizing women's group platforms for improved maternal health awareness in their communities. Themes that emerged include:

1. Better recognition of pregnancy complications among families

2. Despite increased awareness of pregnancy complications, barriers to access persist

3. Contribution of women's group leaders was recognized and appreciated, and

4. Perceived challenges of using women's groups to reach pregnant women.

\section{Better Recognition of Pregnancy Complications Among Women and Their Families}

Women in intervention communities recognize complications (and their consequences) that may develop during pregnancy, and recognize the utility of ANC in preventing, detecting, and treating these early. Common pregnancy complications such as malaria and HDP are now better understood. Convulsion during pregnancy and delivery are now associated with pre-eclampsia as opposed to prior popular beliefs of witchcraft. Some women in the intervention communities attributed eclampsia to convulsion.

"This mama [women leader], when we attended the group meeting on Sunday told us that there is an ailment [that may occur in pregnancy], that will make you shake [demonstrated by shaking her body] like epilepsy."

IDI, women's group participant, age 50

"It will make a woman to shake [chuckles] and die."

IDI, women's group participant, age 23

Some women's group participants report some common pregnancy complications other than HDP that may develop in pregnancy including diabetes, headache, swollen leg, and hemorrhage. Moreover, women learned about early registration and things they need to do to stay healthy during pregnancy.

"We discussed early registration, and they taught us about bleeding during pregnancy, they taught about diabetes, and fever-they taught us many things about ourselves."

IDI, women's group participant, age 36

"Sometimes high blood pressure, convulsion, and swelling of legs, and perceiving constant headache."

IDI, women's group participant, age $\mathbf{4 0}$

Some community men and women in comparison communities continue to associate eclampsia convulsion with other ailments, but overall, care-seeking at health centers or hospitals for these symptoms is growing.

Women's group participants recounted negative outcomes of pregnancy complications (including eclampsia and hypertension), especially for women who do not seek care for HDP. Women report that these may result in death of both the mother and child.

"If the pregnant woman don't go to hospital, maybe the pregnant woman ignored the situation, the thing might cause the baby's death, so anything that happens to the mother affects the baby."

IDI, women's group participant, age 36

Women now appreciate the importance of regular screening for hypertension and proteinuria during ANC.

"They will be treated there if they get there, they check the blood pressure, check their urine, test them and see where really the problem is coming from. They will treat them very well."

IDI, women's group participant, age 40 


\section{Despite Increased Awareness of Pregnancy Complications, Barriers to Access Persist}

Women's group leaders report that women are beginning to understand the importance of ANC services. Accessing ANC services may also be driven by not only a woman's expectations but also by experiences of their neighbors and communities.

"When they see that you have gone [to health facility], and they healed you, other women will also go and the nurses know how to work." IDI, women's group leader, age 31, intervention community

Despite the influence of the WGM platform and peer-education mechanisms, women sometimes face obstacles (mainly financial barriers for medical cost and transportation) in accessing health system support including first ANC visits or re-visits. This is also responsible for the high prevalence of home deliveries.

"Why some women don't like to go for check up at the hospital is because of money. Some nurses especially those ones on duty, when you want to go and deliver a baby, they will give you a long list [of items to buy] which you will not be able to pay, so that makes some women and their husbands not consider delivering in the hospital."

FGD, intervention community men

"If you don't have [money], you cannot go. Maybe you look for someone to borrow [lend] you, if you don't have someone to borrow you, you may decide to stay [at home]. Because they cannot treat you with an empty hand."

IDI, women's group participant, age 36

"Lack of transportation makes them not to go to health center, because some of the people are not living around this area. There are so many living at Kumakumadiahu [neighboring village] all those places, they cannot, sometimes they do not have the transport to come."

IDI, women's group participant, age 27

Women complain of health provider absenteeism and other disrespectful care behaviors when they visit health center, thereby discouraging a repeat visit.

"Some of these women they do complain that they do harass them that will make them not to go to the health center."

IDI, women's group participant, age $\mathbf{4 0}$

Barriers to care also relate to client preferences for health workers who treat them at the health facilities. Some women prefer particular providers despite who is available at the time of visit, which at times, leads to delays and non-use of services.

"I would love to change that nurse and provide someone that will be up and doing, even if you go there at night he will attend to you. The one present here right now does not do anything, if you go there at night he will be complaining that he wants to sleep, they should provide a better health workers."

IDI, women's group participant, age 50

\section{Contributions of Women's Group Leaders Are Recognized and Appreciated}

In-depth interviews with women's group participants indicate that many topics were covered by the women's group leaders while also promoting care seeking. These topics range from bleeding, malaria, hypertension, diabetes, eclampsia, anemia, sepsis, among others. The importance of ANC registration is emphasized in the women's groups as well.

"Like the information they give us the other day is about infection during pregnancy and as a person I experience it in me, so I followed up about what they thought us and actually I got the result."

IDI, women's group participant, age 35 
The dangers of taking un-prescribed drugs and concoctions were emphasized by women's group leaders.

"Formerly, some do use kernel oil and scent leaf they will squeeze it and they put it in the woman's [with PE/E] eye or mouth...according to their beliefs, but now I will not allow somebody to do that to my friend who has something like that, I will carry her to the clinic."

IDI, women's group leader, age 31, intervention community

Some of the women were already experiencing the pregnancy complications discussed during women's group meetings and interactions. These women report that the health information motivated them to seek care at PHCs for their symptoms as seen from the example below of a pregnant woman experiencing symptoms of infection.

"Like the information they give us the other day is about infection during pregnancy and as a person I experience it in me, so I followed up about what they [taught] us and actually I got result [healing]."

IDI, women's group participant, age 36

Group leaders not only present and discuss relevant health information, they also accompany women to the health facilities when the need arises.

"She [women's group leader] told us that a woman that is pregnant if her legs are swollen, we should not stay at home, we should come and meet her then she will carry us to where we will receive care and if you are short of blood [anemic], we should not stay at home, we should come and meet her she will take us there, if we want to give birth, we should not stay at home to drink anything [traditional syrups women drink when in labor] that we don't know, because we can die if we do so. She cautioned us not to do so." IDI, women's group participant, age 50

Women's group leaders encourage male engagement in health seeking. In groups where men were present, for example, in cases where women leaders held sessions at chief's palaces or men served as group secretaries, women's group leaders disseminated information to the men as well. Occasionally, some men request that women leaders visit their homes to talk personally to their pregnant wives. Women leaders also conduct intermittent follow up on the referred pregnant women, emphasizing the role of the women's group platforms in ensuring pregnancy experience.

"Husbands don't have problem with women because we also involve men in that our topic [health information session] so that they will come and see what we are talking so that they will not go and dump their wives in the house." IDI, women's group leader, age 60, intervention community

FGDs in the community and individual perspectives of group participants reveal that some community women understand the role of women's groups in advocating and enabling health seeking, at the individual and family level. For example, mother in laws can influence daughter in laws for ANC care.

“They have seen health to be important because if your daughter in-law is pregnant and doesn't register, you won't be happy. You will like to tell your son please carry someone's child to the hospital to register."

FGD, intervention community women

“My people said let them continue this thing [women's group leaders' health education] because it is helping women."

IDI, women's group participant, age 45

Women appreciated how women's groups leaders disseminated health information through multiple avenues including moving from one church to another, market, committee meetings as well as interpersonal relationships. Women confirmed participating in the group activities repeatedly throughout the implementation period.

"I have listened or attended, like, five times, because she started since last year, she even distributed fliers to us. She will move around from church, road to farm, even when attend the committee meeting, even at home she will be telling us these things."

IDI, women' group participant, age 50 
"Through my mother in-law, and also a retired nurse that is living in our compound, she [mother in-law] has been telling us about it even in the church about the development and also why we need to go health to register."

IDI, women's group participant, age 27

Women's group leaders and participants believe that leaders can keep leveraging the group meetings to provide important health information to the peers.

"As we normally have our meeting, you must be going out, telling others about convulsion and high blood pressure so that everybody will know that there is a problem like that in our life."

IDI, women's group participant, age 35

Overall, women leaders notice that communities are taking action to support health care seeking among pregnant women.

"Communities see such a thing [maternal death] and they are not happy...That's why they push women, they support women and help them with maternity care, they join together."

Woman leader, Intervention community

\section{Residual Challenges in Reaching Women Through Community Platforms}

Not all women live permanently in the community. Some live on farm households detached completely from the communities. Reaching women in farm settlements to provide them with health information or to deliver health services directly to them is a challenge given the logistics involved in reaching remote areas.

"The challenges we have are because many of us are not mobile. We are not mobilized. Me, I am not mobile and if I say I want to go to...ehhn...big plantation [farm settlement] such as Okokoma, I am going to pay 1,000 Naira [about \$4] to reach and another 1,000 Naira to return. This will be difficult for us." IDI, women's group leader, age 53, intervention community

Some women leaders and participants think that providing incentives to the women during health information session may facilitate group meeting attendance and reach larger populations.

"The only thing I want to say is what I have said earlier that if [an NGO] can give out insecticide treated nets or financial support to help them go to the hospital."

IDI, women's group leader, age 46, intervention community

"What I don't like about the health talk is that no money or drugs is given of which I can remember."

IDI, women's group participant, age 45

Some women feel that in as much as the women's group was influential in disseminating important health information to peers, not all women attend the group meetings, and this may limit spread of the health information. Some express their role as WGM participants to additionally serve as ambassadors for mobilizing other women living in their communities.

"The only thing they should do to improve that woman is to empower that woman so that she will have the strength to call other women and to do something that other women will be interested on this meeting so that's what I want them to do. So that other fellow women like me will join us in this meeting."

IDI, women's group participant, age 36 


\section{Discussion}

This implementation research supports the claim that community women's group platforms in Nigeria can play important roles in educating women about their health as well as creating awareness for seeking maternal health services promptly, similar to other settings $5,18,19$. This study's results consistently show that women in the intervention communities are more likely to visit health facilities and access care. It is possible that the increase in women having clinical and relevant laboratory tests is in part due to their increased confidence to both ask questions in addition to actually accessing these services when referred by a care provider27. It may also be associated with facility interventions under the broader Ending Eclampsia project. In instances where women in the intervention communities did not have their vital clinical and laboratory tests completed, explanations often indicated system failures. Frequent stock outs of essential commodities are common in most communities, which was beyond the scope of this project2829. The degree of health care facility functioning in all communities determines whether a woman receives complete care or not.

In addition to improved access to services, women's knowledge and perception of common pregnancy complications, including hypertensive disorders, have improved significantly. Knowledge of dangers signs during pregnancy also differ significantly among the two study groups, with more women in intervention communities exhibiting this knowledge ${ }^{23,30-31}$. Although it is conceivable that women in the intervention group may have obtained information from other sources, qualitative evidence suggests that women's group platforms were unique in offering a peer-to-peer model for increased awareness and agency for initiating a decision to seek care, or demanding quality care once at a facility. It also shows that women's groups may have positive influences beyond their constituent members, to others in community, for promoting early antenatal care and recognition of danger signs, and subsequent care for pre-eclampsia and eclampsia in particular.

Community women and stakeholders recognize the contributions of the learning activities by women's groups. Beyond devoting quality time to women members during meetings, women's group leaders are also emotionally committed to their health and sometimes are willing to escort them to health facilities for care. It appears that providing maternal health information through women's group leaders may have a multiplier effect, as predicated in the Health Belief model. For example, mothers-in-law and spouses who participated in women's group activities relayed the information they received to their daughters-in-law or wives at home.

There were several challenges with the implementation of this intervention. We had anticipated expanding the intervention to more women's groups, but there was a lack of funding by both the government and communities to support women's group leaders. We were unable build further women's group platforms beyond those included in this study. Some communities are predominantly agricultural, and it was difficult to reach women who had migrated due to pastoral or harvest needs during implementation.

Some women's groups had numerous participants, which may have affected the quality of group interactions. The aim of these women's groups was health promotion, however, and more women are reached in larger groups. Further research should be conducted to understand implications of larger versus smaller groups on the effects of health promotion messages. 


\section{Limitations}

This implementation research was for only nine months of a 12 month activity plan, due funding gaps and early cessation of the Ending Eclampsia project. A longer period of implementation could have provided opportunity to learn more about the effects of women's group leaders in increasing uptake of maternal health services. There may be some ancillary effects, as observed from trends in the comparison group, although these may result from broader Ending Eclampsia activities.

Data collection was affected by Joint Health Staff Union industrial actions that led to facility closures for a period of two to three weeks, along with an acute inter-community violent confrontation that led to community exoduses and non-use of health services at affected primary health centers that yielded a low sample size for our exit interviews. Women leaders' log books did not capture the number of times an individual woman attended a women's group meeting, so we were unable to analyze whether there is a dose response.

Finally, given the embedded nature of this study, within the Ending Eclampsia project, other interventions could have contributed to the improved outcomes reported. The implementation of a concurrent primary health care facility-based health education program, whereby a trained health educator communicates essential information to pregnant women waiting for care at facilities, could have contributed to improvements in quality of care. Facility visit rates, particularly for antenatal care, however, were likely influenced by the women's group intervention, given its emphasis on community education in informal settings. 


\section{Conclusion}

Community engagement in Cross River is an important form of information-sharing and awareness creation targeting populations of reproductive age. Participants and leaders in both intervention and comparison communities emphasized the incorporating health education within men's and women's groups, as well as utilizing town criers to encourage women to register for antenatal care and visit primary health care centers for pregnancy-related complications.

During this study there were improvements in knowledge of pregnancy complications, and increased access to maternal health services. Participation in women's group activities among women in intervention communities was associated with improvements in women's knowledge about maternal health complications.

While symptoms of eclampsia, specifically convulsions, are understood, gaps persist in recognition of the signs and symptoms of hypertension and pre-eclampsia, as well as prevention strategies. Women are willing to participate in the health information sessions provided by women leaders during group meetings and in the churches. Community leaders also support the women leaders to leverage such opportunities.

\section{Recommendations}

- Sustain current levels of training and information support to community women's groups to provide community health education;

- Improve training for women's leaders to better disseminate information on the warning signs and symptoms of hypertension and pre-eclampsia, as well as prevention strategies;

- Empower more women to continue health-seeking behaviors through community education on hypertension and pre-eclampsia and eclampsia, to better recognize signs and symptoms of each; and

- Empower women to demand for quality antenatal care services, including asking questions about their health and health care.

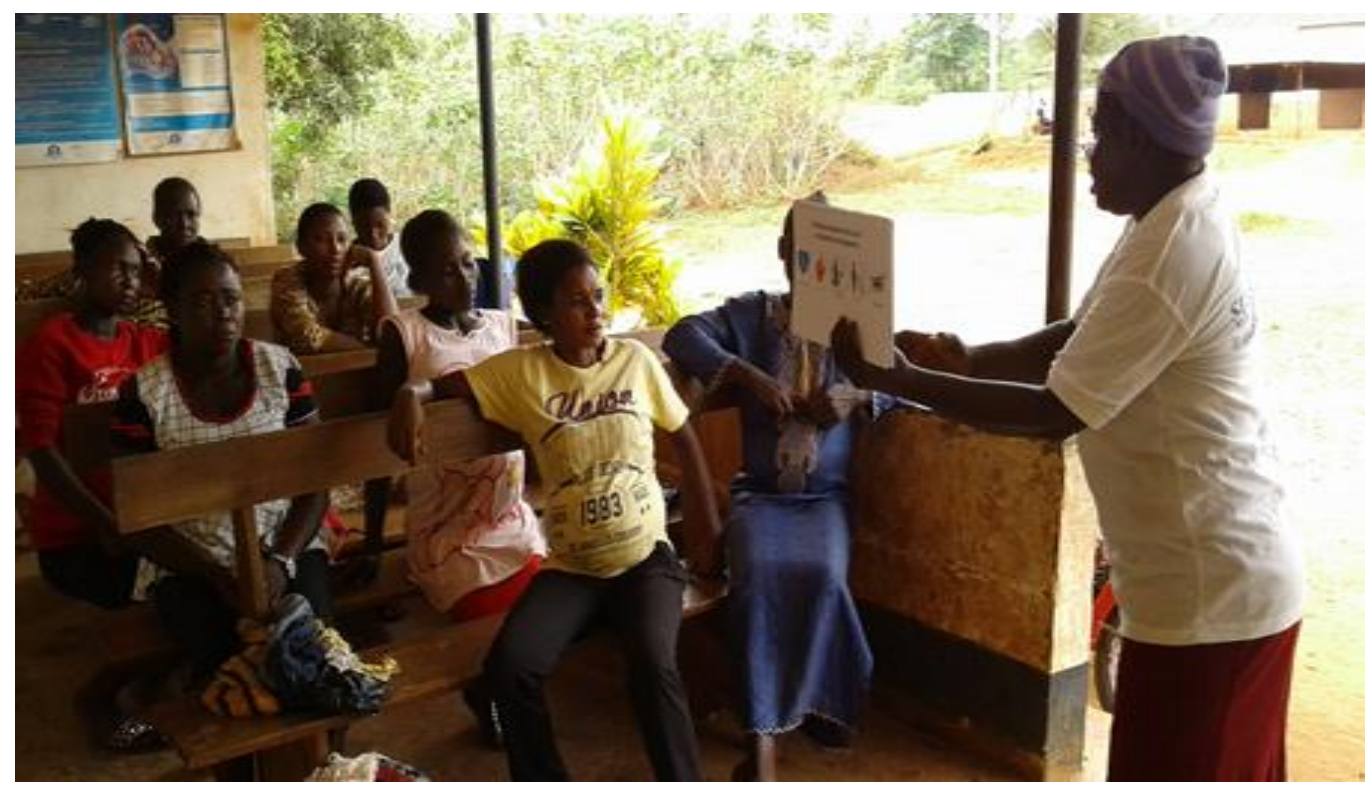




\section{References}

1. Oladapo OT, OO Adetoro, BA Ekele, C Chama, SJ Etuk, AP Aboyeji, HE Onah, AM Abasiattai, AN Adamu, O Adegbola, AS Adeniran, CO Aimakhu, O Akinsanya, LD Aliyu, AB Ande, A Ashimi, M Bwala, A Fabamwo, AD Geidam, JI Ikechebelu, JO Imaralu, O Kuti, D Nwachukwu, L Omo-Aghoja, K Tunau, J Tukur, O Umeora, AC Umezulike, OA Dada, Ö Tunçalp, JP Vogel, AM Gülmezoglu, Nigeria Near-Miss and Maternal Death Surveillance Network. 2016. When getting there is not enough: A nationwide cross-sectional study of 998 maternal deaths and 1451 near-misses in public tertiary hospitals in a low-income country. BJOG 123(6): 928-38

2. Aregbeshola BS, SM Khan. 2017. Primary health care in Nigeria: 24 years after Olikoye RansomeKuti's Leadership. Front Public Health 5: 48.

3. Fagbamigbe AF, ES Idemudia. 2015. Barriers to antenatal care use in Nigeria: evidences from non-users and implications for maternal health programming. BMC Pregnancy and Childbirth 15: 95

4. Fagbamigbe AF, ES Idemudia. 2016. Wealth and antenatal care utilization in Nigeria: Policy implications. Health Care for Women International, 1-4

5. Nwala EK, GN Ebunoha, CU Ugwu. 2013. Consumer knowledge and availability of maternal and child health services: A challenge for achieving MDG 4 and 5 in Southeast Nigeria. BMC Journal of Health Services Research 53

6. Takai IU, HD Dlakwa, M Bukar, BM Audu, AS Kwayabura. 2015. Factors responsible for underutilization of postnatal care services in Maiduguri, north-eastern Nigeria. Sahel Med J 18: 109115

7. Agu U, MC Agu, GA Nnaji. 2015. Utilisation of antenatal services at comprehensive health center umunya, anambra state: a retrospective study. Habert Open Access Journal.

8. Eluwa GIE, R Atamewalena, O Odogwua, A Ahonsi. 2016. Success Providing Postpartum Intrauterine Devices in Private-Sector Health Care Facilities in Nigeria: Factors Associated With Uptake. Glob Health Sci Pract 4(2): 276-283

9. Ensor T, C Green, P Quikley, AR Badru, D Kaluba, T Kureya. 2014. Mobilizing communities to improve health: Results from an intervention in rural Zambia. Bulletin of the World Health Organization 92: 51-59.

10. National Population Commission (NPC) [Nigeria] and ICF International. 2014. Nigeria Demographic and Health Survey 2013. Abuja, Nigeria and Rockville, Maryland, USA: NPC and ICF International.

11. Coleman MA, EK Ansah, IA Agyepong, ED Grobbee, GA Kayode, K Klipstein-Grobusch. 2015. Predictors of skilled attendance at delivery among antenatal clinic attendants in Ghana: A crosssectional study of population data. BMJ Open 5(5).

12. Al-Mujtaba M, LJ Cornelius, H Galadanci, S Erekaha, J Okundaye, OA Adeyemi, NA Sam-Agudu. 2016. Evaluating Religious Influences on the Utilization of Maternal Health Services among Muslim and Christian Women in North-Central Nigeria. BioMed Research International.

13. Mrisho M, B Obrist, JA Schellenberg, RA Haws, AK Mushi, H Mshinda, M Tanner, D Schellenberg. 2009. The use of antenatal and postnatal care: perspectives and experiences of women and health care providers in rural southern Tanzania. BMC Pregnancy and Childbirth 9: 10 
14. Somefun DO, L Ibisomi. 2016. Determinants of postnatal care non-utilization among women in Nigeria. BMC Res Notes 9: 21.

15. Dadelszen PV, LA Magee. 2016. Preventing deaths due to the hypertensive disorders in pregnancy. Best Practice \& Research Clinical Obstetrics and Gynaecology 36: 83-102.

16. World Health Organization (WHO). 2018. WHO Recommendations on Antenatal Care for a Positive Pregnancy Experience: Summary. Geneva: WHO.

17. Afulani PA, M Altman, J Musana, M Sudhinaraset. 2017. Conceptualizing pathways linking women's empowerment and prematurity in developing countries. BMC Pregnancy and Childbirth 17(Suppl 2): 338.

18. Grum T, A Seifu, M Abay, T Angesom, L Tsegay. 2017. Determinants of pre-eclampsia/eclampsia among women attending delivery services in selected public hospitals of Addis Ababa, Ethiopia: A case control study. BMC Pregnancy and Childbirth 17: 307.

19. Sharma S, EV Teijlingen, JM Belizán, V Hundley, P Simkhada, E Sicuri. 2016. Measuring What Works: An Impact Evaluation of Women's Groups on Maternal Health Uptake in Rural Nepal. PLoS ONE 11(5).

20. Prost A, T Colbourn, N Seward, K Azad, A Coomarasamy, A Copas, TAJ Houweling, E Fottrell, A Kuddus, S Lewycka, C MacArthur, D Manandhar, J Morrison, C Mwansambo, N Nair, B Nambiar, D Osrin, C Pagel, T Phiri, A Pulkki-BrännstrÖm, M Rosato, J Skordis-Worrall, N Saville, NS More, B Shrestha, P Tripathy, A Wilson, A Costello. 2013. Women's groups practising participatory learning and action to improve maternal and newborn health in low-resource settings: a systematic review and meta-analysis. Lancet 381: 1736-1746

21. Uneke CJ, CD Ndukwe, AA Ezeoha, HC Urochukwu, CT Ezeonu. 2014. Improving maternal and child healthcare programme using community-participatory interventions in Ebonyi State Nigeria. Int J Health Policy Manag 3(5): 283-287.

22. Zamawe COF, C Mandiwa. 2016. Understanding the mechanisms through which women's group community participatory intervention improved maternal health outcomes in rural Malawi: Was the use of contraceptives the pathway? Global Health Action 9: 30496

23. Warren C, S Ishaku, AB Oginni, G Adoyi, KR Kirk, A Dempsey. 2015. Landscaping analysis for preeclampsia and eclampsia in Nigeria. Abuja: Federal Capital Territory: Population Council.

24. Sripad P, K Kirk, G Adoyi, A Dempsey, S Ishaku, C Warren. Listening at the Frontlines: Qualitative Exploration of Women's Perceptions and Experiences of Pre-eclampsia and Eclampsia in Nigeria through the Health Belief Model. BMC Pregnancy and Childbirth (under review).

25. Okereke E, B Ahonsi, J Tukur, SM Ishaku, AB Ogini. 2012. Benefits of using magnesium sulphate $\left(\mathrm{MgSO}_{4}\right)$ for eclampsia management and maternal mortality reduction: lessons from Kano State in Northern Nigeria. BMC Res Notes 5: 421.

26. National Primary Health Care Development Agency. 2016. Management Guideline for Primary Health Care Under One Roof. www.academia.edu/34977963/The Concept of Primary Health Care under One Roof in Nig eria_final.docx. Assessed 11/7/2019

27. Bluestone J, P Johnson, J Fullerton, C Carr, J Alderman, J Bontempo. 2013. Effective in-service training design and delivery: Evidence from an integrative literature review. Human Resources for Health 11(51): 10. https://human-resourceshealth.biomedcentral.com/articles/10.1186/s12960-019-0350-z 
28. Nditunze L, S Makuza, CL Amoroso, J Odhiambo, E Ntakirumana, L Cedro, J Mushinzimana, B Hedt-Gauthier. 2015. Assessment of Essential Medicines Stock-Outs at Health Centers in Burera District in Northern Rwanda. Rwanda Journal Series F: Medicine and Health Sciences (2)1.

29. Wagenaar BJ, S Gimbel, R Hoek, J Pfeiffer, C Michel, JL Manuel, F Cuembelo, T Quembo, P Afonso, S Gloyed, K Sherr. 2014. Stock-outs of essential health products in Mozambiquelongitudinal analyses from 2011 to 2013. Trop Med Int Health 19(7): 791-801.

30. Bililign N, T Mulatu. 2017. Knowledge of obstetric danger signs and associated factors among reproductive age women in Raya Kobo district of Ethiopia: A community based cross-sectional study. BMC Pregnancy Childbirth 17: 70

31. Loke AY, L Davies, S Li. 2015. Factors influencing the decision that women make on their mode of delivery: The Health Belief Model. BMC Health Serv Res 15: 274. 


\section{Appendices}

\section{Appendix 1. Pictorial job aids used during participatory women's group meetings}

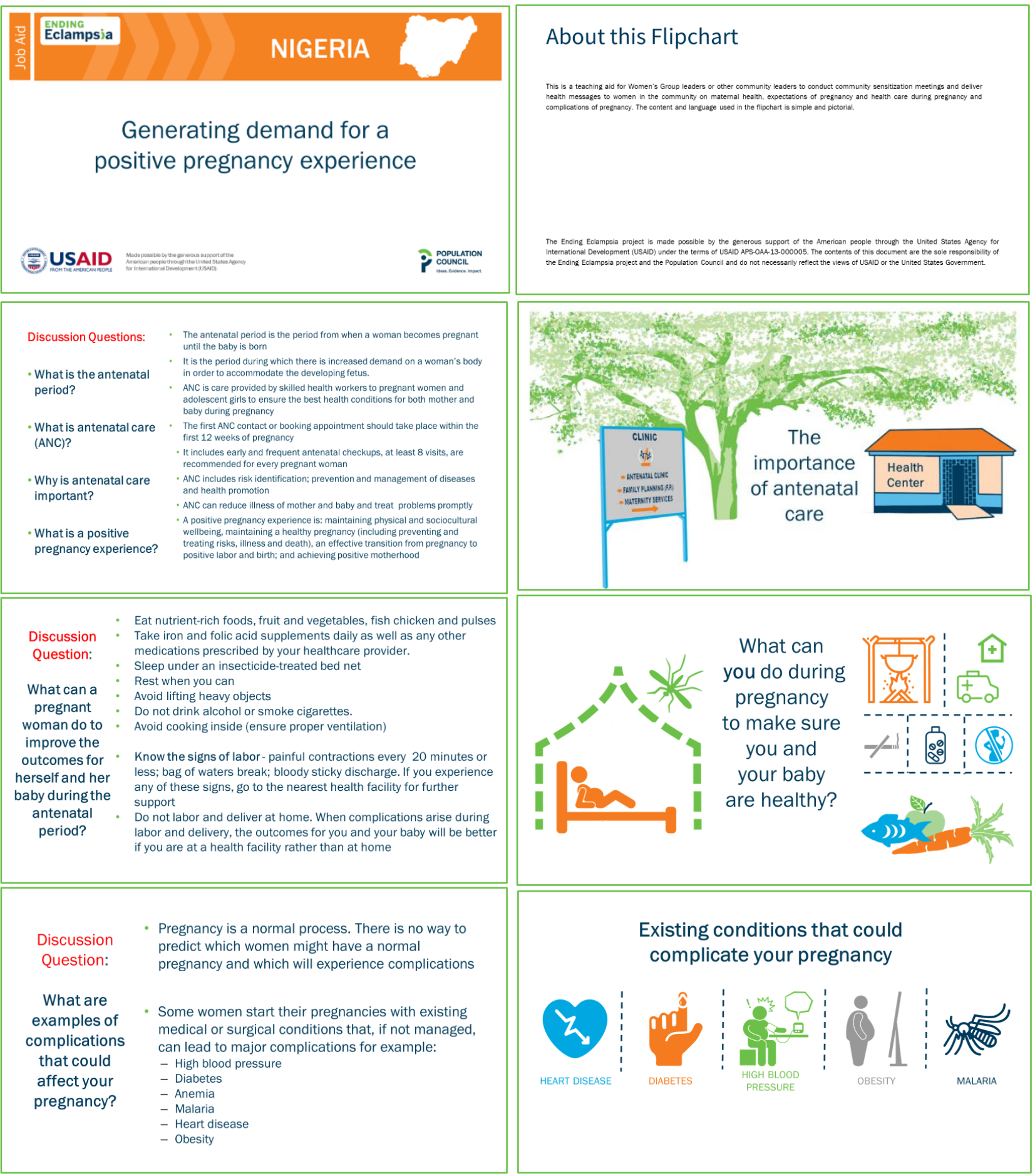




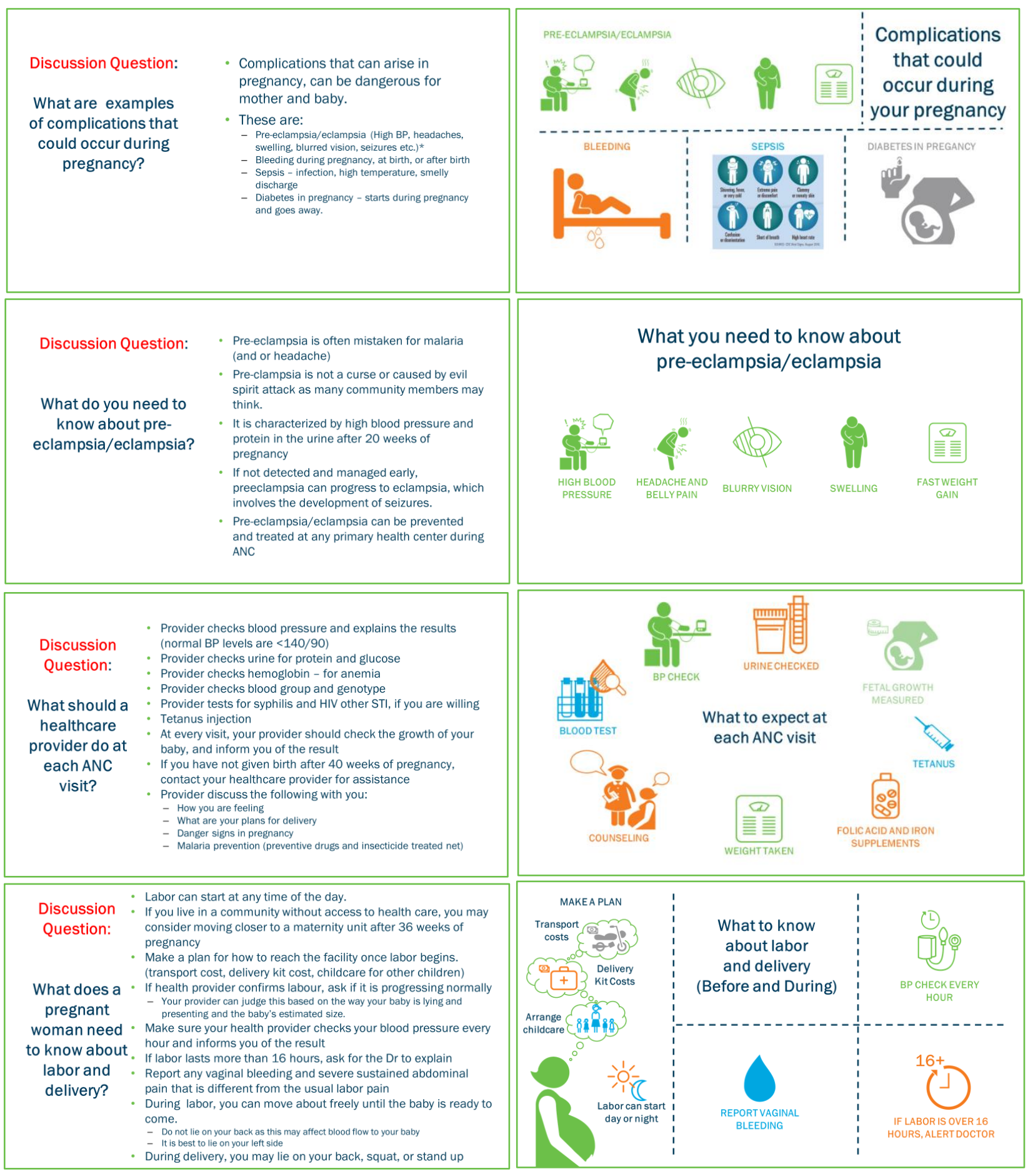




\begin{tabular}{|c|c|}
\hline $\begin{array}{l}\text { What should } \\
\text { a woman do } \\
\text { to take care } \\
\text { of herself and } \\
\text { baby after } \\
\text { delivery? }\end{array}$ & $\begin{array}{l}\text { - As soon as your baby is delivered, make sure the baby is } \\
\text { placed on your tummy, skin-to-skin, even before the baby } \\
\text { is cleaned } \\
\text { - Breastfeeding should begin within } 1 \text { hour } \\
\text { - Report any headache, dizziness, or excessive bleeding, } \\
\text { especially within the first } 24 \text { to } 48 \text { hours after delivery, to } \\
\text { your healthcare provider } \\
\text { - Blood pressure must be checked immediately after } \\
\text { delivery and, at least, twice a day for the first five days } \\
\text { after delivery. } \\
\text { Make sure your blood pressure is normal before leaving } \\
\text { the hospital after delivery. } \\
\text { Your blood pressure must also be checked at 6-8 weeks } \\
\text { after delivery -when you return for baby's postnatal check }\end{array}$ \\
\hline
\end{tabular}

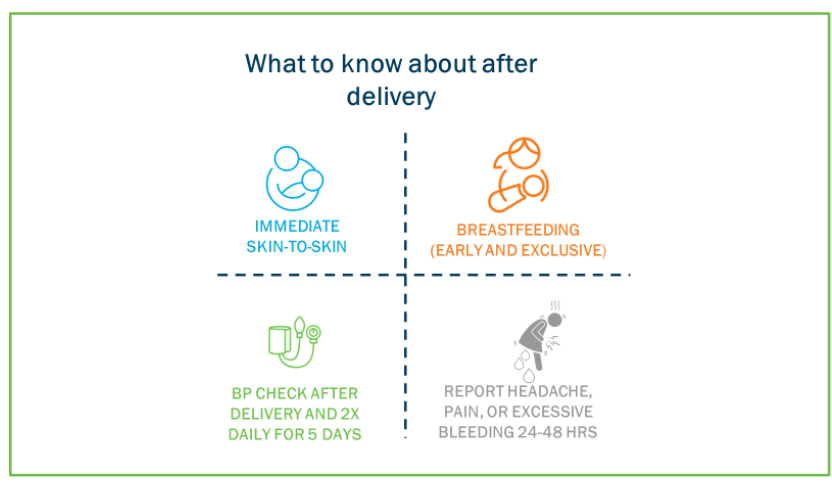

\section{Before you leave the hospital}

- Your baby should be given BCG and polio vaccinations.

Ask for vaccination schedule for your baby up to one year.

Ask your healthcare provider for insecticide-treated bed nets for you and your baby if you did not receive one during your ANC visits.

Register baby's birth and get baby chart
Talk with your provider about infant feeding and the importance of only taking prescribed medicines when breastfeeding. Talk with your provider about family planning methods that can be used while breastfeeding and after.

When to follow-up with your healthcare provider

You must return to your healthcare provider at 2 weeks and 6 weeks after delivery to check the health of both you and your baby. Visit your healthere provider any time the you have a concen provid any tme that you have a concern about your health or
the health of your baby.
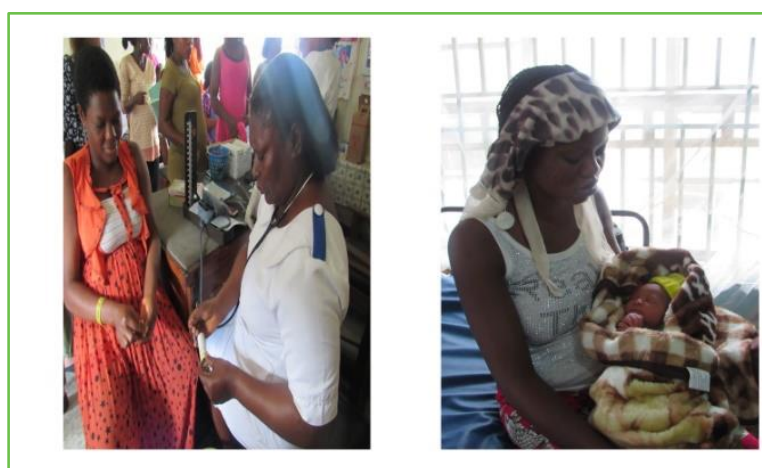
Appendix 2. Profile of Women's Groups in Intervention Communities

\begin{tabular}{|c|c|c|c|c|c|}
\hline & Name of Association & LGA & $\begin{array}{l}\text { Community } \\
\text { Name }\end{array}$ & $\begin{array}{l}\text { Total no of Health } \\
\text { information } \\
\text { sessions } \\
\text { conducted }\end{array}$ & $\begin{array}{l}\text { Total } \\
\text { number } \\
\text { of } \\
\text { contacts }\end{array}$ \\
\hline 1 & Yajele Banem Mkpani Women Association & Yakkurr & Mkpani & 63 & 2772 \\
\hline 2 & Ekori Ntan Women Meeting & Yakkurr & Ekori & 38 & 2,519 \\
\hline 3 & Abini Women Association & Biase & Abini & 3 & 228 \\
\hline 4 & Women of Progress Association & Biase & Iwuru & 23 & 867 \\
\hline 5 & Idundu Anyangansi Women Association & Akpabuyo & Idundu & 6 & 150 \\
\hline 6 & Ikot Uba Women Wssociation & Akpabuyo & Ikot Uba & 4 & 280 \\
\hline 7 & Effangha Affiong Women Association & Akpabuyo & Ikot Effangha & 5 & 210 \\
\hline 8 & $\begin{array}{l}\text { Nka Nti Iban Edet Nsa Women } \\
\text { Association }\end{array}$ & Akpabuyo & Ikot Ekriba & 0 & 0 \\
\hline 9 & AkpapOkoyang Women Association & Odukpanfi & AkpapOkoyang & 0 & 0 \\
\hline 10 & $\begin{array}{l}\text { Atani Eki Women Development } \\
\text { Association }\end{array}$ & Odukpani & Atani Eki & 8 & 149 \\
\hline 11 & Odukpani Women Association & Odukpani & Odukpani & 12 & 789 \\
\hline 12 & Greek Town Women Association & Odukpani & Creek Town & 19 & 694 \\
\hline 13 & Akparabong Women Association & Ikom & Akparaobong & 7 & 176 \\
\hline 14 & Okuni Women Group & Ikom & Okuni & 14 & 501 \\
\hline 15 & Edor Women Group & Ikom & Edor & 3 & 172 \\
\hline 16 & Agbaragba Women Meeting & Ikom & Agbarabga & 6 & 663 \\
\hline 17 & Iyala Nkum Women Association & Obubra & Iyalankum & 4 & 185 \\
\hline 18 & Ababane Women Association & Obubra & Ababane & 0 & 0 \\
\hline 19 & $\begin{array}{l}\text { One Love Committee of Friends, } \\
\text { lyamoyong }\end{array}$ & Obubra & lyamoyong & 17 & 663 \\
\hline 20 & Ekumatax Women Association & Ogoja & Ekumatax & 12 & 2405 \\
\hline 21 & Aya Women Group & Ogoja & Bansara & 28 & 1620 \\
\hline 22 & $\begin{array}{l}\text { Owanakande Women Development } \\
\text { Meeting }\end{array}$ & Yala & Oba & 2 & 196 \\
\hline 23 & Oduche Women Association & Yala & Echumofana & 9 & 322 \\
\hline 24 & Ikoko Women Association & Yala & Ikoko-Mfuma & 6 & 470 \\
\hline
\end{tabular}

